\title{
The Publication of Episodes is moving!
}

The present issue (December 2016) is the final one to be published for IUGS by the Geological Society of India, Bengaluru. The next issue (March 2017) will be published by the Geological Society of Korea. The team in India will continue to process existing papers and receive new submissions until December 1, 2016 after which submissions should go to:

\author{
Dr. Bokyun Ko \\ Managing Editor, 'EPISODES' \\ School of Earth and Environmental Sciences \\ Seoul National University, Seoul 08826, \\ Republic of Korea \\ E-mail: episodes.me@gmail.com
}

From March 2017, Episodes will be published online with printed copies being available on demand. Arrangements for existing and new subscribers will be announced soon. 